\title{
Os egressos do curso de hotelaria: formação e mercado de trabalho
}

CORREIA, Jonilson Costa ${ }^{1}$

\section{RESUMO}

Este estudo apresenta resultados da tese de doutorado em educação e teve como objetivo analisar as percepções dos egressos do Curso de Hotelaria da Universidade Federal do Maranhão sobre sua formação e o mercado de trabalho. $O$ instrumento de coleta foi a entrevista semiestruturada. A análise dos dados foi feita a partir das narrativas dos pesquisados. Para a seleção dos sujeitos investigados utilizou-se os seguintes critérios: os egressos que atuam em diversos setores da hotelaria: meios de hospedagem, hotelaria hospitalar, restaurantes, no ensino de hotelaria e turismo, em enologia e gestão de empreendimento hoteleiro. Ao longo da análise das narrativas percebemos fragilidades, contradições e principalmente lacunas que precisam ser preenchidas, espaços que necessitam ser revisitados pelos professores, pelos alunos de hotelaria da UFMA, pois somente assim, pode haver um diálogo permanente entre academia e mercado de trabalho.

Educação. Mercado de Trabalho. Hotelaria. Maranhão. UFMA.

\section{The graduates of the Hotel Course: formation and labor market}

\section{ABSTRACT}

This study presents the results of the doctoral thesis in education and aimed to analyze the perceptions of graduates of the Hospitality Course of the Federal University of Maranhão about their education and the labor market. The collection instrument was the semi-structured interview. Data analysis was made from the narratives of the respondents. For the selection of the investigated subjects, the following criteria were used: the graduates who work in various hotel sectors: lodging facilities, hospital hotels, restaurants, in the teaching of hotels and tourism, in oenology and hotel management. Throughout the analysis of the narratives we noticed weaknesses, contradictions and especially gaps that need to be filled, spaces that need to be revisited by teachers, by hotel students at UFMA, because only then can there be a permanent dialogue between academia and the job market.

\section{Education. Labor market. Hospitality. Maranhão. UFMA.}

\footnotetext{
1 Professor Adjunto III do Departamento de Turismo e Hotelaria da Universidade Federal do Maranhão. Doutor em Educação pela FaE - UFMG. Mestrado em Educação pela Universidade Federal do Maranhão. E-mail: angrajonilson@yahoo.com.br. Lattes: http://lattes.cnpq.br/7829720263155717. ORCID: https://orcid.org/0000-0003-4719-6517.
} 


\section{Direzione Alberghiera: formazione e mercato del lavoro in Brasile}

\section{RIASSUNTO}

Questo studio mostra i risultati del test di istruzione e l'obiettivo di analizzare due percezioni del corso di Direzione Alberghiera de la Universitá Federale di Maranhao, Brasile, sul mercato della formazione e del lavoro. O strumento de investigazione fu interviste semi-strutturata. Per una selezione de soggetti, sono stati utilizzati i seguenti criteri: il numero di settori dell'ospitalità: ospitalità, ospitalità, ristoranti, turismo, enologia e gestione dell'imprenditoria alberghiera. Sonno state percepitte fragilità, contraddizioni e soprattutto lacune che devono essere risolte, spazi che devono essere rivisti da insegnanti professionisti per permetere un dialogo permanente tra mondo il accademico e mercato del lavoro.

Istruzione. Mercato del Lavoro Ospitalità. Universita Federale do Maranhao.

\section{Los egresados del Curso Hotelero: formación y mercado laboral}

\section{RESUMEN}

Este estudio presenta los resultados de la tesis doctoral en educación y tiene como objetivo analizar las percepciones de los graduados del Curso de Hospitalidad de la Universidad Federal de Maranhão sobre su educación y el mercado laboral. El instrumento de recolección fue la entrevista semiestructurada. El análisis de los datos se realizó a partir de las narraciones de los encuestados. Para la selección de los sujetos investigados, se utilizaron los siguientes criterios: los graduados que trabajan en diversos sectores hoteleros: instalaciones de alojamiento, hoteles hospitalarios, restaurantes, en la enseñanza de hoteles y turismo, enología y gestión hotelera. A lo largo del análisis de las narrativas, notamos debilidades, contradicciones y especialmente brechas que deben llenarse, espacios que deben ser revisados por los maestros, por los estudiantes del hotel en la UFMA, porque solo entonces puede haber un diálogo permanente entre la academia y el mercado laboral.

Educación. Mercado de trabajo. Hospitalidad. Maranhão. UFMA.

\section{INTRODUÇÃO}

A preocupação da sociedade e da comunidade universitária com as exigências do mercado de trabalho em relação aos profissionais formados pelas universidades brasileiras é constante. Quanto a isso Shigunov (2002) 
explica que essa preocupação fica evidenciada nas propostas das diretrizes curriculares dos cursos de graduação e que afetam diretamente a formação profissional em nível superior, assim como na forma que o as empresas selecionam os profissionais.

Os estudos que investigam o fenômeno das atividades características do turismo têm crescido talvez pelo desenvolvimento do setor no mundo e no Brasil. No entanto, é importante salientar que embora haja uma literatura substancial sobre este campo do conhecimento, há ainda um número limitado de estudos realizados sobre o mercado de trabalho turístico, a relação entre turismo e educação, e mais recentemente a respeito da inserção dos egressos no mercado de trabalho.

Nessa perspectiva, Andriola (2014) destaca que raros são os estudos visando o acompanhamento dos egressos de cursos de graduação, realizados pelas IES brasileiras. Este autor ainda salienta que se houvessem mais pesquisas nesse sentido, estas ajudariam a compreender o impacto das ações institucionais na formação dos alunos, as fragilidades da formação oferecida em comparação às exigências do mercado e também as competências desenvolvidas com a formação.

Realizar uma pesquisa com egressos significa acompanhar os caminhos percorridos por eles e, além disso, é uma possibilidade de analisar a educação, em especial sobre a formação propiciada por uma dada instituição, e permite conhecer questões relevantes, como as mudanças no mundo do trabalho, a continuidade na formação e o desenvolvimento profissional do egresso. Essas informações possibilitam à instituição formadora adaptar os currículos e oferecer cursos apropriados às necessidades da sociedade. E ainda, possibilita aos profissionais estabelecer um elo entre a formação e a prática, ao avaliarem o currículo que praticaram e o exercício da profissão (SAKAI, CORSONI JUNIOR, 2008).

Desse modo os estudos de acompanhamento dos egressos do curso de hotelaria trazem pistas que podem iluminar a compreensão das contribuições do processo de formação do hoteleiro na universidade tendo em vista as características e mudanças na natureza e no processo de trabalho, novas formas de ocupação, reconhecimento da inserção e trajetórias dos profissionais, entre outros.

A partir deste pressuposto surgiram as questões: qual a percepção que os egressos do Curso de Hotelaria têm a respeito da sua formação? A formação no Curso de Hotelaria atende as exigências do mercado de trabalho? Quais foram as expectativas dos egressos ao ingressarem no mundo do trabalho? Quais são os saberes necessários para a inserção no mercado hoteleiro? Quais são os desafios e perspectivas da formação em hotelaria na UFMA? 
Tais questionamentos implicam na descoberta de um referencial que contribui para a análise, fundamentação e esclarecimentos sobre o ensino neste campo. Além dessas perguntas mencionadas acima, várias outras podem surgir durante a pesquisa, principalmente porque o caminho da formação em hotelaria ainda é constituído por muitas dúvidas e inquietações, principalmente por se tratar de um campo relativamente recente na academia.

\section{A transição: da universidade ao mercado de trabalho}

A economia e a psicologia do trabalho são as ciências que mais coletam informações acerca da transição de estudantes do ensino superior para o mercado de trabalho, se bem que elas não estão preocupadas primariamente com aspectos educacionais, mas sim com aqueles que dizem respeito ao seu objeto de pesquisa.

As análises das transições pelas quais passam os estudantes de ensino superior - feitas pela psicologia do trabalho - consideram este fenômeno como um processo de mudanças que acompanham o estudante durante todo 0 curso. No entanto estas mudanças se intensificam em dois momentos do curso: logo no momento do ingresso na Educação Superior e posteriormente no final da graduação, ou seja, na ocasião da transição da universidade para a vida profissional. A transição é entendida como "qualquer acontecimento que produza mudanças no nível dos relacionamentos, das rotinas, dos papéis do indivíduo ou possa afetar a ideia ou o conceito acerca de si e do mundo que o rodeia" (SCHLOSSBERG; WATERS; GOODMAN, 1995).

A transição que acontece na entrada para o Ensino Superior é marcada principalmente pelos seguintes desafios: assumir novas funções e responsabilidades e atender às exigências do novo grau de ensino. A transição que ocorre no final do ensino superior é marcada como uma nova etapa da vida do indivíduo, na qual tem de assumir novas responsabilidades, passando a ser o condutor da sua vida pessoal e profissional.

Esse período é marcado pela iminência da formatura e inserção no mercado de trabalho, gerando grandes expectativas, ansiedade e insegurança (DEL PRETRE; DEL PRETRE, 2003). Este momento significa a saída de um ambiente que o estudante passou a conhecer e conviver - o ambiente do Ensino Superior - e o coloca frente aos desafios de um novo cenário, o mundo do trabalho, que é composto por novos tipos de relações e informações, principalmente exigindo habilidades sociais diferentes das desenvolvidas no âmbito da universidade (ALMEIDA; SOARES, 2003).

$\mathrm{Na}$ compreensão de Melo e Borges (2007, p. 378), o período de transição da universidade para o mercado de trabalho é um momento de 
caminhada, de passagem e de construção da vida adulta. Afirmam as autoras: "[...] no período de transição de uma condição de estudantes para profissionais, estes devem ser investigados como um grupo distinto dos demais, identificando-se as particularidades de sua inserção no mercado de trabalho e os obstáculos que vivenciam para manter-se nesse mercado". Bardagi et al. (2004) aponta que algumas características do mercado e das instituições formadoras (escola, universidade) propiciam o estado de ansiedade e insegurança, especialmente a partir dos impasses gerados entre as competências acadêmicas desenvolvidas e as competências requeridas no mundo do trabalho contemporâneo. Por sua vez, para Teixeira (2002) a conclusão de um curso superior marca o fim de uma etapa na educação individual e carrega consigo uma série de expectativas que podem se tornar realidade ou não nos anos que se seguem.

Diante da complexidade das mudanças ocorridas durante o processo de transição entre a universidade e o mercado de trabalho é que se busca neste estudo conhecer as percepções dos egressos do Curso de Hotelaria da Universidade Federal do Maranhão tem sobre a sua formação e o mercado hoteleiro de São Luís - MA. E ao tratar desse fenômeno surge a seguinte questão: o que significa ser egresso de um curso? Em resposta à esta pregunta parte-se do conceito da palavra egresso que é utilizada para designar os indivíduos que concluíram cursos e/ou qualquer capacitação profissional em qualquer tipo de instituição ou entidade, por exemplo, escolas públicas ou particulares, universidades etc. É uma indicação de que frequentou o curso e se afastou após a conclusão.

No âmbito educacional, existe divergência quanto à definição do termo egresso, pois alguns estudiosos referem-se exclusivamente aos alunos formados; outros abrangem a denominação a todos os indivíduos que saíram do sistema escolar, sejam eles ex-alunos: diplomados, por desistência, por transferência ou jubilados. Ferreira (2004) o considera, no âmbito educacional, como sendo o indivíduo que cumpriu o currículo de um curso de graduação ou pós-graduação e obteve uma titulação em determinada área do conhecimento. Analisando o termo egresso contido na legislação da área educacional, entende-se como sendo a pessoa que efetivamente concluiu os estudos, recebeu o diploma e está apto a ingressar no mercado de trabalho (BRASIL, 1996).

No entanto, a legislação específica, como a LDB 9.394/96 e o Decreto no 2.208/97, fazem referência a egressos de uma forma ampla; são todos os indivíduos que saíram do sistema escolar de diferentes formas: diplomados, desistentes, transferidos ou jubilados. A partir dos conceitos e critérios utilizados na definição do termo egresso, importa expor o que a legislação fala sobre egressos, bem como as políticas institucionais aplicadas para 0 acompanhamento e gestão de egressos. 
Diante disso, as Instituições de Ensino Superior (IES) precisam repensar a formação dos profissionais, com intuito de adequar os Projetos Pedagógicos (PP), conforme preconizado nas Diretrizes Curriculares Nacionais dos Cursos de Graduação (2003), em que é estabelecido como perfil do profissional/egresso. No caso do egresso do curso de Hotelaria as Diretrizes dizem o seguinte: "um hoteleiro deve estar apto a atuar em um mercado altamente competitivo e em constante transformação, com impactos periódicos ou sazonais, segundo as mudanças na vida social, econômica, política, empresarial e organizacional, com ênfase na Gestão e Administração de Hotéis com os mais diversos e importantes aspectos estruturais, infraestruturais e 0 seu eficaz e qualitativo funcionamento, de acordo com os diversos segmentos culturais da demanda hoteleira".

\section{O percurso metodológico}

Este estudo foi de natureza qualitativa, cuja abordagem "verifica uma relação dinâmica entre o mundo real e o sujeito, isto é, significa compreender o mundo dos seres humanos, o que pensam, desejam, o que sabem e o que pretendem fazer. Suas crenças e suas convicções não são excluídas e não podem ser estimadas como algo externo ao assunto abordado (MORIN e DIÁZ 2016).

Neste caso optou-se pela pesquisa qualitativa, a fim de analisar como os egressos do curso de hotelaria percebem a sua formação e o processo de inserção no mercado de trabalho. A partir da abordagem qualitativa emergem elementos que ajudam a captar a essência do fenômeno estudado e a dinâmica do seu acontecimento.

Para Godoy (1995) a pesquisa qualitativa parte de questões ou focos de interesses amplos, que vão se definindo à medida que a desenvolve. Esta envolve a obtenção de dados descritivos sobre pessoas, lugares e processos interativos pelo contato direto do pesquisador com a situação estudada, procurando compreender os fenômenos segundo a perspectiva dos sujeitos, ou seja, dos participantes da situação em estudo.

Diante do problema dessa pesquisa, 'as percepções dos egressos do curso de hotelaria da Universidade Federal do Maranhão sobre sua formação e a inserção no mercado de trabalho', foi feita também uma pesquisa descritiva. Segundo Duarte \& Furtado (2002, p. 29) a pesquisa descritiva caracteriza-se por ser um método de investigação que "descreve um fenômeno ou situação mediante um estudo realizado em determinado contexto espacial e temporal". Além disso, porque visa a compreensão ampla do fenômeno que está sendo estudado, considera que todos os dados da realidade são importantes e devem 
ser examinados. O ambiente e as pessoas nele inseridas devem ser olhados holisticamente: não são reduzidos a variáveis, mas observados como um todo.

Este trabalho está compreendido em duas fases. No primeiro momento ocorreu o levantamento teórico-bibliográfico sobre a temática, da qual delineouse o objeto a ser analisado. A leitura da bibliografia deve ser um exercício de crítica, na qual são destacadas as categorias usadas pelos diferentes autores. Este é, segundo Goldenberg (2007, p. 79), "um exercício de compreensão fundamental para a definição da posição que o pesquisador irá adotar". Também é um momento de buscar e fazer descobertas teóricas como forma de enriquecimento teórico metodológico do trabalho.

Em seguida realizou-se a coleta de dados através de entrevista no primeiro semestre de 2018. Esta técnica foi bem apropriada, pois foi possível extrair, das atitudes e respostas dos participantes do grupo, sentimentos, opiniões e reações acerca do tema. Kvale (1996) explica que, a "Entre Vista" é uma maneira de reunir as diversas opiniões das pessoas. Entrevistar é um modo de sacudir as evidências, sacudir aquilo que é familiar, sacudir aquilo que se está acostumado a ver e assim problematizar o obvio. A entrevista com os egressos do curso de hotelaria teve esse propósito, de ver o que há por trás das experiências dos alunos. Significou atingir as partes mais escondidas dessas experiências e suas fronteiras como sentimentos, esperanças, ambições, frustrações, temores e coisas que não podem ser ditas em público, por exemplo.

Para incluir evidências empíricas tomou-se como campo de pesquisa a Coordenação do em Hotelaria da Universidade Federal do Maranhão considerando a viabilidade concedida institucionalmente para o acesso a documentos que favorecessem o desenvolvimento da pesquisa, bem como dados sobre os egressos. A partir de algumas informações contidas na Coordenação do Curso, tais como endereço de e-mail e número do telefone foi possível contatar de imediato alguns dos egressos, outros contatos foram feitos através de redes sociais através do nome completo destacado em seu dossiê na coordenação.

Os sujeitos envolvidos na pesquisa foram os egressos do Curso de Hotelaria graduados em anos diferentes, e foram contatados de forma aleatória. Participaram das entrevistas apenas 10 (dez) egressos que trabalham em diversos setores da hotelaria: meios de hospedagem, hotelaria hospitalar, restaurantes, ensino de hotelaria e turismo, em enologia e gestão hoteleira. O critério de escolha, ou seja, de inclusão desses egressos na pesquisa foi ser bacharel em hotelaria pela UFMA, e ter pelo menos um ano de graduação.

\section{Achados da pesquisa}


Nesta parte, apresentam-se as narrativas dos egressos do Curso de Hotelaria da UFMA que participaram da pesquisa. Mas que são estes egressos?

Com a finalidade de responder à esta pergunta, serão apresentados dois conjuntos de dados dos sujeitos participantes. Primeiro um breve resumo do perfil de cada um, colocando idade, ano da graduação, e um pouco da trajetória profissional. Em segundo, narrativas dos participantes sobre a escolha do curso. A pesquisa contou com a participação de 10 sujeitos. Deste total, sete foram do sexo feminino e três do sexo masculino.

O número de sujeitos que a pesquisa contou foi influenciado principalmente pela agenda dos participantes, isto é, suas disponibilidades no que tange a seus compromissos e afazeres. Em segundo, pela própria essência da técnica utilizada (entrevista).

Para resguardar a privacidade dos egressos, escolheu-se para os inquiridos nomes das luas do Sistema Solar. Segundo Bogdam e Biklen (2002), as identidades dos sujeitos devem ser protegidas, para que a informação que 0 investigador recolhe não possa causar-lhes qualquer tipo de transtorno ou prejuízo.

A partir da tabela 01 é possível observar que dos dez entrevistados predomina a faixa etária de 24 a 30 anos, a maioria, ou seja, $70 \%$ do grupo. Segundo pesquisa do IPEA (2015), o predomínio de ocupados que têm entre 25 e 49 anos de idade é maior no segmento do turismo que na Economia em geral. A porcentagem destes ocupados no turismo e na economia é semelhante em todas as regiões. A menor concentração desta faixa etária é no Sul, com 64\% dos empregados do turismo (IPEA, 2017).

Quanto à formação continuada também maioria dos sujeitos da pesquisa está preocupada em continuar estudando depois da graduação em hotelaria, sendo os cursos de gestão os mais procurados, $40 \%$. Dentre os participantes somente dois são mestres e dos dois, apenas um foi se especializar na área de hospitalidade.

Para Kuenzer (1997, p. 73) a nova roupagem econômica exige "o desenvolvimento da capacidade de educar-se permanentemente e das habilidades de trabalhar independentemente, de criar métodos para enfrentar situações não previstas, de contribuir originalmente para resolver problemas complexos".

Quanto à inserção no mercado de trabalho, a tabela mostra que apenas dois sujeitos não atuam na área, os demais estão no mercado de trabalho desde que formaram, percebo a partir das narrativas que os alunos que fizeram em estágios não obrigatórios durante o curso tiveram oportunidade de ingresso 
no mercado com mais cedo. O lugar de atuação desse grupo é diverso, desde hotel, restaurante (Alimentos e Bebidas), universidade (ensino), empreendedorismo (próprio negócio) e hotelaria hospitalar. Isso mostra como o mercado de trabalho hoteleiro é repleto de opções, e dinâmico no sentido de que está sempre abrindo oportunidades.

Tabela 01 - Síntese do Perfil dos egressos do Curso de Hotelaria/Entrevistados

\begin{tabular}{|c|c|c|c|c|c|}
\hline Sujeito & Sexo & Idade & Graduação & Pós-Formado & Atualmente \\
\hline Ganimede & Feminino & 27 & Hotelaria & $\begin{array}{c}\text { Especializaçã } \\
\text { o em Hotelaria } \\
\text { Hospitalar }\end{array}$ & $\begin{array}{l}\text { Assistente de } \\
\text { reservas } \\
\text { Grupo } \\
\text { Pestana - SP }\end{array}$ \\
\hline Titã & Feminino & 29 & Turismo/Hotelaria & $\begin{array}{c}\text { Especializaçã } \\
\text { o em Gestão } \\
\text { da } \\
\text { Hospitalidade }\end{array}$ & $\begin{array}{c}\text { Recepção do } \\
\text { Hotel San } \\
\text { Fernando }\end{array}$ \\
\hline Callisto & Masculino & 58 & $\begin{array}{c}\text { Administração/Hotel } \\
\text { aria }\end{array}$ & --------------- & $\begin{array}{l}\text { Assessor } \\
\text { parlamentar }\end{array}$ \\
\hline Umbriel & Masculino & 28 & Turismo/Hotelaria & $\begin{array}{l}\text { Mestrado em } \\
\text { Hospitalidade }\end{array}$ & $\begin{array}{l}\text { Professor } \\
\text { Substituto do } \\
\text { DETU/UFMA }\end{array}$ \\
\hline Ariel & Masculino & 24 & Hotelaria & - & Maitre \\
\hline Io & Feminino & 24 & Hotelaria & $\begin{array}{c}\text { Especializaçã } \\
\text { o em Gestão } \\
\text { Hospitalar }\end{array}$ & $\begin{array}{c}\text { Supervisora } \\
\text { de Hotelaria } \\
\text { Hospitalar }\end{array}$ \\
\hline Dione & Feminino & 29 & Hotelaria & $\begin{array}{l}\text { Curso de } \\
\text { Sommelier }\end{array}$ & Sommelier \\
\hline Oberon & Feminino & 28 & Hotelaria & $\begin{array}{l}\text { MBA em } \\
\text { Marketing e } \\
\text { Vendas }\end{array}$ & $\begin{array}{l}\text { Diretor } \\
\text { Comercial }\end{array}$ \\
\hline Titania & Feminino & 34 & Hotelaria & $\begin{array}{l}\text { Mestrado em } \\
\text { Políticas } \\
\text { Públicas }\end{array}$ & $\begin{array}{c}\text { Professora } \\
\text { Substituta } \\
\text { DETUH/UFM } \\
\text { A }\end{array}$ \\
\hline Rhea & Feminino & 30 & Hotelaria & $\begin{array}{l}\text { MBA em } \\
\text { Gestão de } \\
\text { Pessoas }\end{array}$ & $\begin{array}{c}\text { Supervisora } \\
\text { de Eventos e } \\
\text { Recepção }\end{array}$ \\
\hline
\end{tabular}

Fonte: Elaborada por Correia (2018).

Com a finalidade de ser o mais fiel possível às falas e percepções dos egressos do Curso de Hotelaria, assim como aos objetivos propostos para o desenvolvimento da pesquisa buscou-se a análise narrativa na perspectiva oral como base para interpretação dos dados coletados.

Trabalhar com narrativas na pesquisa é partir para a desconstrução/construção das próprias experiências, tanto do pesquisador como do sujeito da pesquisa. Exige que a relação dialógica se instale criando em cumplicidade de dupla descoberta. Outro aspecto importante destacado por 
Cunha (1998) é de que o trabalho com as narrativas é profundamente formativo e nesta direção afirma que:

Esta compreensão, provavelmente, é que tem feito a pesquisa qualitativa tornar-se, mesmo sem intensão precípua de fazer uma intervenção, em uma alternativa de formação. Ao mesmo tempo em que o sujeito organiza suas ideias para o relato quer escrito, quer oral - ele reconstrói sua experiência de forma reflexiva e, portanto, acaba fazendo uma autoanálise que Ihe cria novas bases de compreensão da sua prática (CUNHA, 1998, p. 39).

A narrativa é a expressão da experiência humana. E para Costa (1997) "narrar é (re) construir verbalmente o presente, as lembranças, os desejos, é (re) elaborar a experiência invisual no passado comum" (p.8), a narrativa como método está longe de certezas.

Portanto, a escolha deste método surge como uma alternativa aos procedimentos teórico-metodológicos desta pesquisa capaz de contribuir para a compreensão das falas dos sujeitos participantes sobre sua trajetória, suas práticas, e refletir, remirar e inter-relacionar ideias e sentimentos. Diante deste contexto, saber por meio das narrativas o que pensam os egressos do curso de hotelaria a respeito da sua profissão é fundamental para o desenvolvimento de uma avaliação sobre o curso e o mercado de trabalho.

A inserção dos egressos do Curso de Hotelaria da Universidade Federal do Maranhão no mercado de trabalho se inicia bem antes de concluírem a graduação, ou seja, de acordo com os relatos abaixo, observa-se que, inicialmente, alguns iniciaram no mercado através dos estágios.

Quando eu saí da universidade eu já estava empregada em um hotel, foi onde eu fiz o estágio obrigatório (Hotel SESC Olho D’Água), e o estágio me proporcionou entrada nesse hotel, no início foram dois anos de contrato, porque lá é seletivo para trabalhar. Lá eu passei por todos os setores como governança, reservas, gerência, administrativo, restaurante, turismo. Depois desses dois anos no SESC eu fui trabalhar em restaurante (Don Irdara) como recepcionista e depois de seis messes a empresa fez uns cortes, muitas pessoas foram demitidas e fui uma delas. Saindo desse emprego eu trabalhei como auxiliar de concierge em um condomínio e lá também passei seis meses. Então fiquei vagando no mercado, adquirindo experiências, tentando me identificar com uma dessas áreas, mas ai foi quando que terminei o mestrado que decidi passar pela docência, agora estou como professora substituta no curso de hotelaria da UFMA (Titania).

Durante o Estágio I eu fiquei quinze dias na Le Pizzeria (emprego atual) e antes de terminar o estágio a gerente me 
chamou e perguntou se eu gostaria de fazer "extra" lá sendo que seria remunerado, passei a ir três vezes por semana. Nesse período teve o seletivo de estágio para o SESC e passei como estagiário/bolsista no Hotel SESC Olho D'água e lá eu passei pela governança, recepção, turismo social, reservas, isso me deu outra visão de hotelaria, pois só conhecia a parte de $A$ e $B$, fiquei dois anos no SESC sempre pela manhã. Depois disso o pessoal da Le Pizzeria me chamou novamente e comecei a trabalhar lá como funcionário efetivo. Alguns meses depois me promoveram para Maitre responsável pelo salão, e pelo gerenciamento do estoque, das compras, a base de hotelaria me ajudou. Ainda não consegui fazer uma pósgraduação, mas ainda tenho vontade de fazer um mestrado (Ariel).

A fala de Ariel corrobora com o que diz Alarcão (1996), ou seja, o estágio como uma experiência de formação estruturada e como um marco fundamental na formação e preparação dos alunos para a entrada no mundo profissional. $O$ estágio na vida do egresso foi uma experiência de aproximação com a realidade de sua profissão, bem como facilitadora de sua permanência no mercado de trabalho.

Comecei como estagiária, ainda era aluna do curso de hotelaria, trabalhava meio período porque estava no quinto semestre da faculdade, eu trabalhei no Rio Poty Hotel e depois no Hotel Luzeiros, em ambos na recepção, aprendi muita coisa de hospedagem. Eu consegui essa vaga de estágio porque nas férias eu distribuía currículo e descobri que no Poty precisavam de estagiários, fiz entrevista e permaneci dois anos lá, nesse período participei de um seletivo no Hospital UDI para trabalhar com hotelaria hospitalar, eu passei e fui contratada como trainee, depois fui efetivada (lo).

Desde o primeiro período do curso que os professores incentivavam os alunos a conhecer o mercado através das práticas, dos estágios, e essas atividades abrem portas. Mas eu desde o primeiro período comecei a procurar vagas de estágio e a partir disso fiz alguns estágios. Comecei estagiando no Hostel Solar das Pedras, e lá eu estagiei nas reservas e recepção, era um estágio não obrigatório e fiquei por lá durante dois anos, era remunerado. Depois disso fiz um estágio na Pousada Portas da Amazônia na área de A e B onde eu organizava café da manhã, eventos, e depois trabalhei com Volga Cerimonial Eventos que faz todo tipo de eventos, lá eu era recepcionista, e no Hotel Luzeiros eu fiz o estágio obrigatório. Em todos esses momentos eu dava opinião, pois como fazia hotelaria o pessoal sempre pedia sugestões. Um pouco antes de apresentar a monografia, eu consegui um teste no Grand São Luís Hotel e logo fui contratada e estou até hoje na empresa (Rhea). 
Como bem explica a interpretação da sociologia econômica e Segundo Granovetter (1995), os profissionais utilizam três formas de encontrar oportunidades de trabalho: meios formais (propagandas, agências de emprego públicas e privadas, concursos e seleções patrocinadas por universidades ou por associações profissionais), contatos pessoais e contato direto com a organização. A maioria dos postos disponíveis é encontrada de modo informal, por meio de amigos, colegas ou familiares, pelos quais os indivíduos são informados do surgimento de novos postos. (GRANOVETTER, 1995).

Entrei na UFMA, e chegando lá eu pensei que se ficasse só nas aulas eu não ia crescer então eu fiz contatos com pessoas que já trabalhavam na área e que podiam me dar oportunidade de estágio, e ai foi assim que consegui uma vaga para estagiar na Pousada Portas da Amazônia, onde passei três meses no setor de reservas, isso era o primeiro semestre de hotelaria, eu percebi que ali era pequeno e que não correspondia as minhas expectativas, então consegui um estágio no Mercure Mont Blanc que era do grupo ACCOR uma rede francesa que estava em São Luís, e nesse estágio eu tinha bolsa, foi uma grande experiência para mim, fiquei um ano e meio por lá, deixei o estágio e fui me dedicar ao curso. Me envolvi com projetos de extensão e pesquisa no NUPPHO, no ESINT. Depois de um ano fora dos estágios eu comecei a colocar curriculo em hotéis de São Luís e fui chamado pelo grupo Solare, para trabalhar no setor comercial, depois disso fui para o Quality Grand São Luis Hotel, Brisamar e Grupo BHG que havia comprado o Solare. Faz três anos que abri uma consultoria no ramo de hotelaria e sou sócio proprietário do Softwin Hotel (Oberon).

Para Borges (2002), o estágio deve ser analisado como um momento de aplicação de habilidades, competências e conhecimentos, oportunizando a vivenciar situações complexas de ensino-aprendizagem, propor executar, avaliar, reformular e refletir sua atuação, apresentando alternativas de solução para seu desempenho no processo educativo.

No primeiro semestre do curso comecei logo a estagiar, consegui a vaga através de uma amiga que o marido era gerente na Pousada Portas da Amazônia, o estágio era remunerado e passei por esse estágio durante três meses como apoio de recepção. Isso foi muito importante porque estava no começo dos estudos e me ajudou a ter noção de mercado. (Ganimede). Fui bolsista do NUPPHO por dois anos, além disso, fui estagiária na Pró-Reitoria de Extensão d UFMA. Depois tranquei a matrícula e fui para Dublin na Irlanda fazer intercâmbio. Ao retornar um ano depois eu concluí a graduação e em seguida já estava trabalhando em uma pousada, lá fiquei por três meses e como era uma empresa familiar tinham regras que não me deixavam a vontade para colocar meus conhecimentos em prática, lá eu era a governanta, 
recepcionista, ajudava no café da manhã. Decidi mudar para São Paulo onde moro e trabalho. Hoje atuo na Central de Reservas do Grupo Pestana (Ganimede).

Ao longo da graduação com o intuito de minimizar essa distância com o mercado e não ficar focado apenas na universidade eu fiz vários estágios. Eu sempre optei por fazer estágios em São Luís em grandes redes como Holiday Inn, Pestana Hotel e sempre nos setores de recepção e governança. Quando eu concluí o curso fui direto para a Escola Castelli de Hotelaria fazer especialização e como lá eles direcionam para o mercado eu tive a oportunidade de estagiar na rede ACOOR como trainee, mas assim que terminei 0 estágio decidi entrar no mestrado onde fiz estágio docência e tive a oportunidade de orientar alunos da graduação em TCC, depois do mestrado prestei seletivo para professor substituto no Departamento de Turismo e Hotelaria da UFMA e hoje estou lecionando (Umbriel).

As narrativas acima têm como ponto comum a experiência do estágio, que representa a oportunidade de entrar em contato com o mercado de trabalho, de forma a complementar e aperfeiçoar competências profissionais por meio da ligação entre o sistema educacional e o mundo laboral.

O estágio evidencia as características da profissão, pois é a fase em que o aluno coloca em prática os conhecimentos adquiridos em sala de aula, conhecimentos técnicos e teóricos da formação. Além disso, favorece ao aluno maior familiaridade com os conteúdos abordados nas aulas (LOPES; TELES; PATRÍCIO, 2016). Durante o estágio, aprende-se a lidar com responsabilidades, respeitar regras, trabalhar a pontualidade e superar metas. Também, o estágio ameniza a passagem da vida estudantil para o mundo do trabalho.

Para o estudante de hotelaria o estágio tem grande relevância por ser um espaço de prática que não existe no curso e essa carência os motiva a buscar fora da universidade essa vivência. Ao colocar os pés no Ensino Superior, muitos estudantes começam a pensar na primeira oportunidade de estágio na área escolhida, considerando-o porta de entrada para o mercado de trabalho.

Ansarah (2001) Ao falar sobre a educação universitária em turismo pontua o seguinte:

Infelizmente não existe hoje a preocupação voltada para a consciência crítica dos alunos, tampouco para 0 desenvolvimento do pensamento crítico, mas sim do imediatismo profissional, da sua experiência prática tão requisitada pelo mercado de trabalho. (ANSARAH, 2001, p. 13). 
Diferente dos demais a aluna Titã em sua trajetória acadêmica não fez estágio não obrigatório antes de ingressar no mercado, mas suas experiências práticas se deram a partir dos projetos de extensão e pesquisa em núcleos dos cursos de Turismo e Hotelaria, sua entrada no mercado se deu pela entrega de currículos em hotéis de São Luís.

Durante a UFMA eu não trabalhei formalmente, mas sempre estive engajada em projetos de extensão e pesquisa como bolsista do ESINT que abriu um seletivo e abriram vagas para hotelaria e eu passei. Foi ali que aprendi a fazer planos de aula, para dar cursos no interior sobre hotelaria, hospitalidade, e da área de turismo, e fiquei no ESINT uns três anos. Formei, e comecei a colocar currículos e fui chamada para o Hotel Abbville onde trabalhei na recepção e depois reservas. Eu saí do Abbville, e fui para o Hotel San Fernando que tem um horário mais adequado para eu estudar francês e fazer outras coisas. A mudança de emprego foi automática de um hotel para outro (Titã).

A extensão universitária é uma prática aliada da aprendizagem acadêmica que ajuda os alunos a aprimorar o conhecimento adquirido ao longo da graduação, além de melhorar a autoconfiança, proporcionar o conhecimento profissional na área escolhida. Deslandes e Arantes (2017) apontam que empresas ao recrutarem trainees preferem aqueles que estiveram inseridos na comunidade, vivenciando e colocando em prática o seu aprendizado.

Para Morin e Diaz (2016) a educação está no centro da vida social, da reprodução e da geração de conhecimentos, da criação do novo e da conservação do passado. Nesse sentido, a extensão universitária mostra a importância de sua existência na relação estabelecida entre instituição e sociedade. Isso acontece por meio da aproximação, da troca de conhecimentos e experiências entre professores, alunos e população, também pelo desenvolvimento dos processos de ensino e aprendizagem. A partir de práticas cotidianas, aliadas ao ensino e a pesquisa e, especialmente, pelo fato de propiciar o confronto da teoria com o mundo real, de necessidade e desejos (HENNINGTON, 2005).

Ao observar o turismo em São Luís - MA, verifica-se que é preciso desenvolver as ações de extensão nos cursos de Turismo e Hotelaria da UFMA que busquem desenvolver nos alunos e na comunidade o valor "do bem receber", assim como oportunizar qualidade no atendimento com mão de obra qualificada, e amenizar os problemas enfrentados no setor de turismo da cidade.

A medida que os egressos foram conhecendo a sua profissão e 0 ambiente de trabalho eles perceberam que a atividade hoteleira é permeada de desafios. Wada (2006) aponta desafios do mercado hoteleiro tais como: a 
formação para atuar na hotelaria familiar (independente); ser hospitaleiro; os baixos salários; e a falta de um plano de carreira para o profissional de hotelaria, assim como o reconhecimento da profissão.

O primeiro grande desafio do setor hoteleiro é uma progressiva profissionalização do conjunto de serviços que abriga. É certo que o maior profissionalismo dos serviços, certamente, quebra o conservadorismo de empresas familiares, assim como as experiências mais bem-sucedidas dos hotéis familiares geram inovações na gestão dos hotéis (WADA, 2006).

Um segundo desafio é a característica de ser hospitaleiro. Pois há clientes que não querem hospitalidade. Ao contrário, querem o anonimato - as chaves, os recados, a roupa, tudo no horário e ponto final. O que fazer, então? A hospitalidade compreende, assim, um vasto arco de posturas que o hoteleiro deve adotar diante de clientes que querem, exclusivamente, o serviço hoteleiro indispensável - e, nesse sentido, o desafio é a oferta de um bom serviço de recepção e hospedagem - e daqueles que buscam a "experiência" - e nesse caso, o calor humano, o verdadeiro, é a pedra de toque do serviço (WADA, 2006).

Se a responsabilidade recai sobre as pessoas, há que se pensar, adicionalmente, nos sistemas de formação de pessoal para a hotelaria. Um dos subprodutos decorrentes do crescimento da oferta hoteleira no país foram os diversos tipos de cursos de formação - técnicos, graduações, cursos sequenciais, MBAs e cursos de extensão - já que, tradicionalmente, ao ser um setor de "gente que lida com gente", é considerado um setor de potencial oferta de postos de trabalho. Mesmo com esses cursos, a necessidade de aprimorar a mão-de-obra permanece.

Nesse sentido os egressos apontam que:

Um dos principais desafios é um pouco difícil lidar com os empresários, pois se você se destaca em sua função eles têm medo de lhe dar oportunidades, tento que os altos cargos ficam com eles, isso é um desafio, porque mesmo sendo capacitado, as promoções funcionais dentro de uma hotel de São Luís quase não acontece, mesmo e você estudou, fez uma pósgraduação e etc. isso se torna um desafio (Rhea).

Como eu trabalhei em duas empresas familiares, um dos grandes desafios é que nestes meios de hospedagem não se tem liberdade de atuar, não há estrutura adequada de lazer e serviços para o hóspede como acontece em hotéis de rede (Titan).

No Brasil, segundo Cypriano (2014) a oferta hoteleira é majoritariamente independente. Muitos desses meios de hospedagem independentes são 
administrados por famílias que empreenderam um negócio hoteleiro, mas sem nenhuma ou pouca formação e informação sobre o segmento.

A gestão de meios de hospedagem independente e familiar envolve uma estrutura organizacional bastante enraizada e de difícil mudança. No Maranhão, esta fatia do mercado hoteleiro é predominante, quase não há hotéis de rede na cidade de São Luís, e como os próprios entrevistados relataram este é um desafio pelo fato de as empresas independentes deixarem o atendimento, hospitalidade, e a formação e promoção do profissional do turismo/hotelaria em segundo plano. É preciso reconhecer que a hotelaria além de ser responsável pela hospedagem dos visitantes/turistas é também responsável pela imagem que é passada ao turista. Imagem positiva ou não, da hospitalidade recebida e do povo que habita a cidade.

\section{Considerações finais}

Este trabalho foi realizado a partir das percepções dos egressos do curso de Hotelaria da Universidade Federal do Maranhão, identificando quais os desafios, oportunidades e fragilidades da formação e de que forma ela contribui para o processo de inserção no mercado de trabalho.

A discussão em torno da inserção dos egressos no mercado de trabalho e sua formação mostra que devido a ausência de laboratórios e um hotelescola no curso de hotelaria da UFMA levou a maioria dos entrevistados desde o início do curso encontrar no estágio não obrigatório oportunidades de pôr em prática o que aprendem em sala de aula, assim como conhecer o mercado de trabalho e inserir-se nele. No entanto, Fávero (1995), ressalta que a universidade não deve somente habilitar pessoas para o mercado de trabalho, mas formar homens, cidadãos e profissionais - homens pensantes - que busquem continuamente novos caminhos e que sejam capazes de influir sobre a realidade onde vão atuar, numa perspectiva de mudança, a partir de uma visão crítica desta realidade.

A partir dos resultados também percebe-se que há uma heterogeneidade entre os egressos do curso em relação a gênero, dado relevante na medida em que, demonstra uma procura pelo curso predominantemente feminina. A amostra foi composta por 10 egressos na faixa etária dos 24 a 30 anos; $70 \%$ do sexo feminino, $30 \%$ do sexo masculino e formaram-se entre os anos de 2010 e 2017. Desta amostra dois não trabalham na sua área de formação, um não está empregado. Dentre os pesquisados existe um percentual significativo de empregados no segmento de hotelaria, estes egressos estão inseridos em vários setores como hospital, restaurante, central de reservas, meios de hospedagem e ensino superior. Os dados também mostram a preocupação que os entrevistados tiveram em continuar os 
estudos depois de formados, sendo que a maioria já possui pelo menos uma pós-graduação lato sensu direcionada para sua área de atuação.

Percebe-se que o campo de atuação para o profissional de hotelaria está em expansão apesar dos desafios e barreiras da profissão. A hotelaria é uma profissão dinâmica e por isso é necessário adequar-se constantemente às exigências impostas pelas transformações sociais no contexto onde ela está inserida.

No entanto ainda é evidente no curso de hotelaria os alunos pensarem em uma formação instrumentalizada, voltada apenas para o mercado de trabalho, presa ao saber-fazer, nesse sentido é preciso olhar a realidade e mobilizar-se em torno de uma educação mais humana, crítica e reflexiva.

Por isso é importante repensar permanentemente o papel da escola, a teoria pedagógica, a didática, os currículos, a organização escolar, a relação professor-aluno. Repensar a empresa hoteleira, os processos produtivos, as mudanças tecnológicas ali incorporadas, os processos de qualificação/ desqualificação da mão-de-obra, a exploração (ou não) do trabalhador, com o objetivo de formar um senso crítico capaz de produzir mudanças, transformando as denúncias vazias em propostas de ação que possam de fato melhorar a relação educação, trabalho e escola.

\section{REFERÊNCIAS}

ALARCÃO, I. Formação reflexiva de professores: estratégias de supervisão. Porto: Porto Editora, 1996.

ALMEIDA, L. S. SOARES, A. P. Os estudantes universitários: sucesso escolar e desenvolvimento psicossocial. In: MERCURI, E.; POLYDORO, S. A. J. Estudantes universitários características e experiências de formação. 1. ed. Taubaté: Cabral Editora e Livraria Universitária, 2003.

ANDRIOLA, W. B. Estudo de egressos de cursos de graduação: subsídios para a autoavaliação e o planejamento institucionais. Educar em Revista, Curitiba, n. 54, p. 203-219, out./dez 2014.

ANSARAH, M. G. dos R. Teoria Geral do Turismo. In.: ANSARAH, M. G. dos R. (Org.). Turismo: como aprender, como ensinar. São Paulo: SENAC, 2001.

BOGDAM, R.; BIKLEN, Sari. Investigação qualitativa em educação. Portugal: Porto Editora, 2002.

BORGES, Z. S. Estágio Curricular: atividade teórico-prática. In: QUADROS, C. de.; AZAMBUJA, G. (Org.). Formação de professores em serviços: a experiência da UNIFRA. Santa Maria: UNIFRA, 2002. 
BRASIL. Lei no 9.394, 20 de dezembro 1996. Diretrizes e Bases da Educação Nacional. Disponível em: portal. mec.gov.br/arquivos/pdf/ldb.pdf. Acesso em: 18 ago. 2016.

COSTA. C. B. Uma história sonhada. Revista Brasileira de História, São Paulo, v. 17, n. 34, p. 52-65, 1997.

CUNHA, M. I. da. O professor universitário na transição de paradigmas.

Araraquara: JM Editora, 1998.

CYPRYANO, P. Desenvolvimento hoteleiro no Brasil: panorama de mercado e perspectivas. São Paulo: SENAC, 2014.

DEL PRETRE, Z.; DEL PRETRE, A. No contexto da travessia para o ambiente de trabalho: treinamento de habilidades sociais com universitários. Estudos de Psicologia, v. 8, p. 413-420, 2003.

DESLANDES, M. S. S.; ARANTES, A. R. A extensão universitária como meio de transformação social e profissional. Sinapse Múltipla, v. 6, n. 2, p. 179-183, dez. 2017.

DUARTE, S. V.; FURTADO, M. S. V. Manual para elaboração de monografias e projetos de pesquisa. 3. ed. Montes Claros: Ed. Unimontes, 2002.

FERREIRA, A. B. H. de. Novo Aurélio século XXI: o dicionário da língua portuguesa. 3. ed. Rio de Janeiro: Nova Fronteira, 2004.

GODOY, A. S. Introdução à pesquisa qualitativa e suas possibilidades. Revista de Administração de Empresas, v. 35, n. 2, p. 57-63, mar./abr. 1995.

GOLDENBERG, M. A arte de pesquisar: como fazer pesquisa qualitativa em Ciências Sociais. 10. ed. Rio de Janeiro: Record, 2007.

KUENZER, A. Ensino de 2ºrau: O trabalho como princípio educativo. 3. ed. São Paulo: Cortez, 1997.

KVALE, S. An introduction to qualitative research interviewing. Thousand Oaks: Calif; Sage, 1992.

LOPES, K. M. V.; TELES, M. M. R.; PATRÍCIO, P. C. de S. (Org.). Estágio supervisionado em computação: reflexões e relatos. 1. ed. Curitiba: Apris, 2016.

MORIN, E.; DÍAZ, C. J. D. Reinventar a educação: abrir caminhos para a metamorfose da humanidade. São Paulo: Athena, 2016.

SAKAI, M. H; CORDONI, L. J. Os egressos da medicina da Universidade Estadual de Londrina: sua formação e prática médica. Revista espaço para Saúde, Londrina, v.6, p. 34-47, dez. 2004, p.34-47, Disponível em: http://www.ccs.uel.br/espacoparasaude. Acesso em: 10 out. 2017.

SCHLOSSEBERG, N. K.; WATERS, E. B. GOODMAN, J. Counseling adults in transition. New York: Springer Publishing Company, 1995. 
Os egressos do curso de hotelaria: formação e mercado de trabalho

SHIGUNOV NETO, A.; MACIEL, L. S. B. (Org.) Currículo e formação profissional nos cursos de turismo. Campinas: Papirus, 2002.

WADA, E. K. Os desafios da hotelaria. GV Executivo, v. 5, n.1, jan./fev. 2006. 